\title{
Levels, Isomer Profiles, and Estimated Riverine Mass Discharges of Perfluoroalkyl Acids and Fluorinated Alternatives at the Mouths of Chinese Rivers
}

\author{
Thanh Wang, ${ }^{*}, \dagger$ Robin Vestergren, ${ }^{\S, \|}$ Dorte Herzke, ${ }^{\S}$ Junchao Yu, and Ian T. Cousins ${ }^{\ddagger}$ \\ ${ }^{\dagger}$ MTM Research Centre, School of Science and Technology, Örebro University, Örebro, Sweden \\ ${ }^{\ddagger}$ State Key Laboratory of Environmental Chemistry and Ecotoxicology, Research Center for Eco-Environmental Sciences, Chinese \\ Academy of Sciences, Beijing 100085, China \\ ${ }^{\S}$ Norwegian Institute for Air Research (NILU), FRAM - High North Research Centre on Climate and the Environment, Tromsø, \\ Norway \\ "ACES - Department of Environmental Science and Analytical Chemistry, Stockholm University, Stockholm, Sweden
}

Supporting Information

ABSTRACT: An extensive sampling campaign was undertaken to study the levels, isomer profiles and riverine mass discharges of perfluoroalkyl acids (PFAAs) and fluorinated alternatives in 19 Chinese rivers. The levels and homologue profiles of $\Sigma_{10}$ PFAAs varied considerably among the 19 rivers (mean 106; median 16.3, range 8.9-1240 ng/L), indicating the influence of specific point sources. Highly branched isomer profiles of perfluorooctanoic acid (18-25\% br-PFOA) in rivers with elevated concentrations $(96-352 \mathrm{ng} / \mathrm{L})$ indicate that releases during production of PFOA by electrochemical fluorination and/or its use in fluoropolymer manufacture were the dominant sources to these rivers. The fluorinated alternatives 6:2 fluorotelomer sulfonate (detection frequency $21 \%,<0.1-3.1 \mathrm{ng} / \mathrm{L}$ ) and chlorinated polyfluoroalkyl ether sulfonate F-53B $(51 \%,<0.56-78.5 \mathrm{ng} / \mathrm{L})$ were also found in some rivers. The total Chinese riverine mass discharges of PFOA (mean 80.9; range 16.8-168 t/y) (including monitoring data from this and other studies) were in good agreement with theoretical PFOA emission estimates (17.3-203 t/y) whereas riverine mass discharges of PFOS (mean 3.6; range 1.9-5.6 t/y) could only account for a minor fraction of theoretically estimated PFOS releases $(70 \mathrm{t} / \mathrm{y})$. This study provides empirical evidence that emissions from Chinese point sources likely dominate the global emissions of several legacy PFASs (notably PFOA) and fluorinated alternatives (e.g., F-53B).

\section{INTRODUCTION}

Per- and polyfluoroalkyl substances (PFASs) are a broad group of synthetic chemicals with unique amphiphilic properties that can effectively lower the surface tension of aqueous solutions. ${ }^{1}$ Their surfactant properties and chemical stability have made them particularly useful in numerous industrial applications such as in polymerization aids, chrome metal plating and electronics manufacturing, as well as active ingredients in consumer products such as textile, paper, leather and firefighting foams. ${ }^{2}$ Although PFASs fill many important functions in modern society, the resistance to degradation of the $\mathrm{C}-\mathrm{F}$ bond and thus the perfluoroalkyl moiety means that all PFASs ultimately degrade to form environmentally persistent products. ${ }^{3}$ Among these stable degradation products, particular attention has been directed to the long-chain perfluoroalkyl acids (PFAAs) such as perfluoroalkanesulfonic acids (PFSAs, with 6 or more perfluorinated carbons) and perfluoroalkyl carboxylic acids (PFCAs, with seven or more perfluorinated carbons) due to their bioaccumulation potential and toxicity. ${ }^{1}$ National regulatory actions have thus been imposed on the long-chain PFAAs in some countries and various international actions have also been taken. For example, the production and use of perfluorooctanesulfonate (PFOS) (as well as related perfluorooctane sulfonyl fluoride (POSF)-based substances) is now restricted under the Stockholm Convention on Persistent Organic Pollutants, and an extensive phase-out of perfluorooctanoic acid (PFOA) and other long-chain PFCAs and related chemicals has been completed by many of the main manufacturers. ${ }^{4}$

The increasing public awareness of their risks and stricter regulations on PFASs in North America and Europe has, however, also led to a geographical shift in production and usage to regions with less stringent chemical regulations. ${ }^{4}$ For

Received: July 27, 2016

Revised: September 30, 2016

Accepted: September 30, 2016

Published: September 30, 2016 
example, the production of PFOS in China increased rapidly around the year 2000 and is currently steady at about 100-200 tonnes/y. ${ }^{5-7}$ For long-chain PFCAs, the ongoing yearly production and use in China has been estimated to be equivalent to or even exceeding that in Europe and North America prior to the stewardship program. ${ }^{2,8}$ At the same time, numerous fluorinated alternatives to PFOS and long-chain PFCAs have been developed internationally (both within and outside of China) and many of these have been used and released in China. These fluorinated alternatives are generally shorter chain versions of their predecessors, but for every longchain PFAS there are typically several different fluorinated alternatives being used. ${ }^{9,10}$ Some of the major alternatives to PFOS in the chrome metal plating industry are perfluorobutanesulfonate (PFBS) based substances, 6:2 fluorotelomer sulfonate (6:2 FTS) and 2-[(6-chloro-1,1,2,2,3,3,4,4,5,5,6,6dodecafluorohexyl)oxy]-1,1,2,2-tetrafluoroethanesulfonate, typically referred to by its trade name F-53B (CAS No. 7360619-6). ${ }^{9,11,12}$

Previous research has demonstrated that accurate identification and quantification of PFAS emission sources to the environment is very complex due to the numerous uses and modes of emission throughout the life-cycle of products. ${ }^{2}$ Additionally, the degradation of precursors ${ }^{13}$ may substantially contribute to the emissions of PFAAs to the environment. ${ }^{14}$ Given this complexity, theoretical emission estimates based on production volumes and various assumptions regarding use and emission factors are subject to large uncertainties. ${ }^{2,15,16}$ Estimating emissions in China is especially challenging given the different production and use patterns of PFASs compared to Europe and North America and a recent rapid rise in PFAS manufacturing. ${ }^{5,8}$ One approach to empirically evaluate emissions involves measuring the PFAA levels at the mouths of rivers and calculating the mass loadings of chemicals to the ocean (hereafter referred to as riverine mass discharges). This methodology has previously been employed to evaluate theoretically derived emission estimates of PFCAs from Europe. ${ }^{17}$ One drawback of this approach is that atmospheric deposition of PFAAs to rivers originating from degradation of volatile precursors is not taken into account, although this is expected to be a minor input to rivers receiving industrial discharges of PFAAs. ${ }^{14,18}$ In addition to riverine mass discharge studies, isomer profiling has been suggested as a source apportionment tool to distinguish between the two major synthesis routes to produce PFOA. ${ }^{19,20}$ The isomer profiling tool has been successfully applied to differentiate between PFOA derived from electrochemical fluorination (ECF) and telomerization sources in ocean water and remote Arctic lakes. ${ }^{19,20}$ Recent studies have also characterized the isomer profiles in technical PFOA products from China and also applied isomer profiling in some Chinese river samples close to manufacturing sources. ${ }^{21-23}$

Although an increasing number of river monitoring data of PFASs has recently been reported on a regional scale in China, ${ }^{24-27}$ an extensive national field-based emission estimate is currently not available. The overarching goal of this study was therefore to systematically investigate the levels, isomer profiles and riverine mass discharges of PFAAs and some fluorinated alternatives from major Chinese rivers with the aim of identifying the main emission sources. These measurements will facilitate an evaluation and refinement of emission estimates of PFAAs, which is a prerequisite for determining the impact of Chinese emissions on global PFAA transport and fate. The study further provides the first nationwide empirical riverine data as well as emission estimates for some key fluorinated alternatives in China.

\section{MATERIALS AND METHODS}

Study Design and Sampling. The study design was similar to that of McLachlan et al., ${ }^{17}$ which used surface water samples taken at river mouths as an integrated measure of upstream emission sources in Europe. One of the key assumptions for this methodology is that PFAAs, which have a high to moderate water solubility, are transported unimpeded (i.e., they are not retained or degraded) to the ocean. ${ }^{21,26}$ Water samples taken at the river mouth would therefore provide an integrated measure of sources to the catchment (domestic discharges and industrial discharges). In this study, the combined riverine water flow of all sampled rivers at their mouths was estimated to be about $37400 \mathrm{~m}^{3} / \mathrm{s}$ on an annual average basis, which roughly represents $70 \%$ of the total riverine water flow discharging to estuaries in China (see Supporting Information (SI) Table S3).

Nineteen rivers were included in this study; the Daliao, Shuangtaizi, Daling, Xiaoling, Luan, Yongding, Hai, Yellow, Jia, Yangtze, Huangpu, Qiantang, Yong, Jiao, Ou, Min, Jin, Jiulong, and Pearl River (Figure 1). The Shuangtaizi and Daliao are distributaries of the Liao River which is one of the largest river systems in China, and the watershed is an important industrial base for heavy machinery, metal refining and chemical manufacturing. The Yellow River is the second longest river $(5460 \mathrm{~km})$ in China and is notable for the high load of silt it carries to the ocean. Two sites were sampled along this river at a distance of around $100 \mathrm{~km}$ from each other (site 1 and 2, Figure 1). The Yangtze River is the largest river $(\sim 6300 \mathrm{~km})$ in China and its runoff $\left(\sim 29100 \mathrm{~m}^{3} / \mathrm{s}\right)$ accounts for about half of the national riverine flow discharging to estuaries. Three sites were therefore sampled (sites 3, 4, and 5) along the eastern part of the river to investigate potential spatial differences. The Huangpu River $\left(\sim 315 \mathrm{~m}^{3} / \mathrm{s}\right)$ is the most eastern tributary of the Yangtze River and their confluence point (upstream of site 5) is located near the estuary of the East China Sea. The Huangpu River was treated as a separate river since the reported riverine flow for the Yangtze River was from a sampling station upstream of the confluence point. The Pearl River is the collective name for the watersheds of the Xijiang (not sampled in this study), Beijiang and Dongjiang Rivers since they share a common delta (Pearl River Delta, PRD), and the river system is ranked second in China in terms of annual riverine flow to the estuary $\left(\sim 10000 \mathrm{~m}^{3} / \mathrm{s}\right)$. Samples were collected along the Beijiang (site 6, sample PR1, PR2) and near the Humen Bridge (site 7, PR3) where the Beijiang and Dongjiang intersect before flowing into the South China Sea with an annual riverine flow to the estuary of $\sim 1900 \mathrm{~m}^{3} / \mathrm{s}$. Other rivers including Hai, Yongding, Yong, Ou, Daling, Xiaoling, and Qiantang were primarily selected due to suspected emission sources of PFASs.

The sampling campaign was conducted during the low flow season between late July and October 2013. Sampling procedures were based on the protocol described by McLachlan et al. ${ }^{17}$ with some modifications. Written instructions together with wide mouth polyethylene (HDPE) bottles ( $1000 \mathrm{~mL}$, Nalgene, Thermo Scientific) were sent to the participants. The sampling personnel were instructed to sample water at preselected sites that were mostly close to the mouth of the rivers (Figure 1), but to avoid sampling at sites 

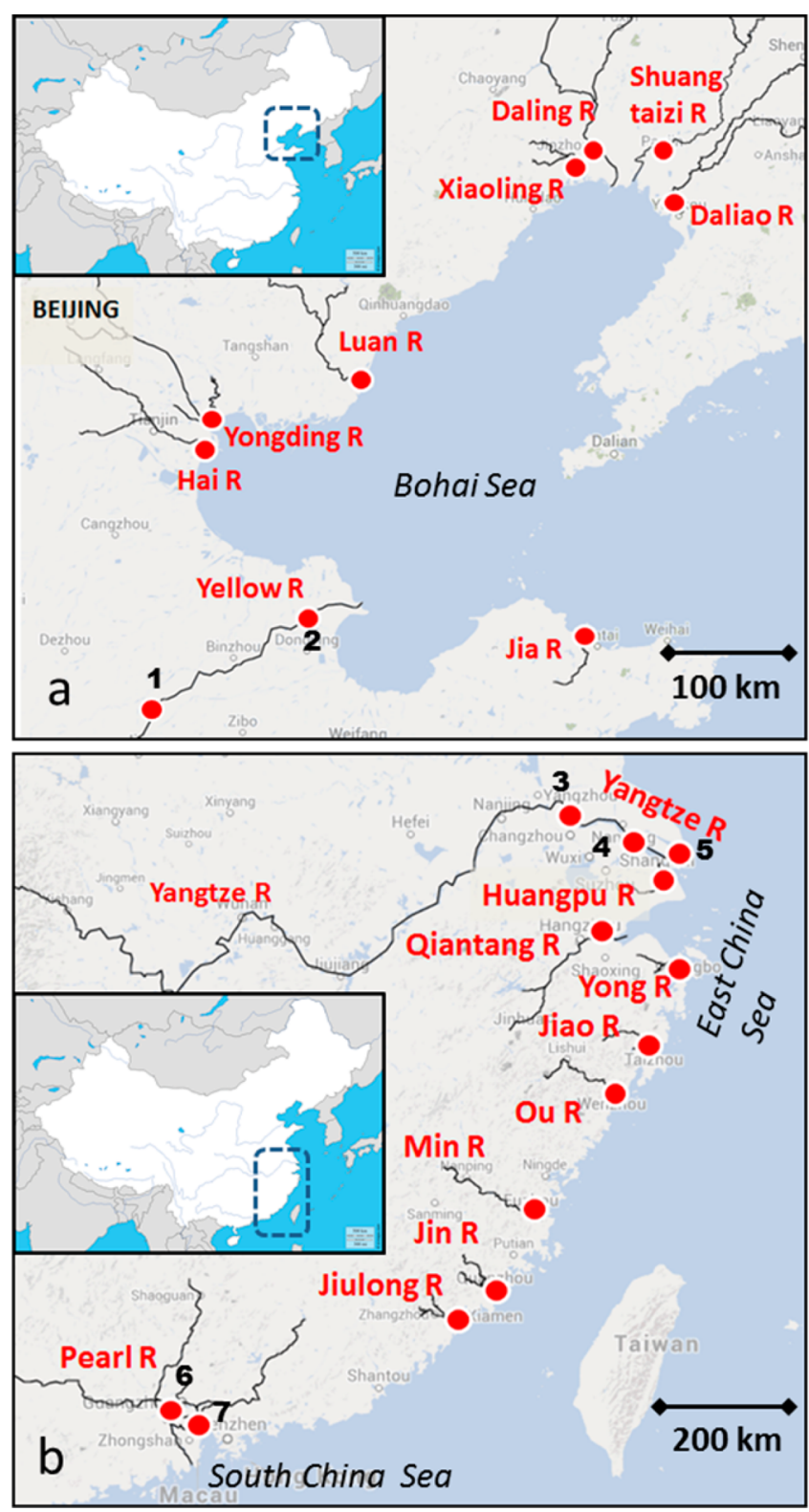

Figure 1. Illustration of the sampling sites on the different coastal rivers of China. Only the outmost eastern sections of the rivers are outlined.

influenced by seawater or adjacent to known point sources. River water collection was conducted during low tide events and if possible on both sides of the river. Samples were collected approximately $0.5-1 \mathrm{~m}$ below the water surface. The bottles were rinsed twice with the river water before final collection. Information was collected about the sampling time and site (either as GPS coordinates or marked in maps). A field blank was included by filling a bottle with Millipore water and opening for approximately $5 \mathrm{~min}$ during the sampling event. The collected samples were then sent to our laboratory as soon as possible by express delivery. Using this protocol, it was not possible to store samples frozen until they arrived in the Beijing laboratory. For each river, 2-5 water samples were collected giving a total of 53 samples (SI Table S4).

Standards and Reagents. A total of 12 PFASs were included in this study and full names of the analytes can be found in SI Table S1. Standards for 6:2-FTS, PFBA, PFPeA,
PFHxA, PFHpA, PFOA, PFNA, PFDA, PFBS, PFHxS, PFOS, and technical PFOA (T-PFOA) with a given composition of linear (79\% L-PFOA) and branched isomers (9\% iso-PFOA, $3 \%$ 3m-PFOA, 4\% 4m-PFOA, 4.5\% 5m-PFOA) were purchased from Wellington Laboratories Inc. The labeled standards M26:2FTS, M3PFBA, MPFHxA, MPFOA, M3PFHxS, MPFOS, and M4PFHpA were also purchased from Wellington. F-53B was kindly donated by Dr. Jun Huang at Tsinghua University, and had a stated purity of $\geq 98 \%$.

Instrumental Analysis and Quantification. A detailed description of the sample pretreatment method can be found in the SI. In brief, the water samples were first filtered through a polyethersulfone (PES) filter, spiked with labeled internal standards and then purified using an Oasis WAX SPE eluted with basic $\mathrm{MeOH}$. The eluate was solvent exchanged to $980 \mu \mathrm{L}$ water:MeOH mixture (9:1, v/v), and finally $20 \mu \mathrm{L}$ of labeled M4PFHpA was added as a volumetric standard. Two different instrumental methods were used to quantify PFASs in water samples. The separation and quantification of the 12 PFASs was performed on a Dionex UHPLC (Ultimate 3000) coupled with an AB Sciex Triple Quad 5500 mass spectrometer. For isomer specific separation and quantification of branched PFOA isomers, a modified LC-MS/MS method to that of Benskin et al. was used. ${ }^{28}$ Details of both analytical methods can be found in the SI.

QA/QC. A number of measures were taken to ensure accurate detection and quantification of PFAAs and the fluorinated alternatives. Sorption tests of the sampling bottles were conducted by filling them $(n=3)$ with $1 \mathrm{~L}$ Milli-Q water and spiking with native standards to a final concentration of $100 \mathrm{ng} / \mathrm{L}$. Bottles were stored at room temperature for 2 weeks, and then pretreated using the above method without the filtration step. No significant adsorption was observed for the short-chain PFAAs as well as PFOA and PFHxS. An average of $16 \pm 6 \%$ of the initial amount of PFOS was adsorbed onto the surface of the sampling vessel, while for PFNA and PFDA the adsorption was $5 \pm 1 \%$ and $14 \pm 3 \%$, respectively. Also, sorption onto the PES filter might further lead to underestimation of the dissolved concentrations, especially for longchain PFAAs, although a previous study ${ }^{29}$ showed that this was mostly $<15 \%$ for the PFAAs included in our study. Spikerecovery tests of surface water samples $(n=10)$ demonstrated a high level of accuracy (mean recovery $69-112 \%$ ) and precision (RSTD 6-28\%) for the majority of analytes (see SI Table S2). However, for PFBS and PFDA the recoveries were $163 \pm 39$ and $53 \pm 15$ respectively indicating that the quantified concentrations of these substances should be regarded as semiquantitative. Procedural blanks $(n=10)$ were performed in parallel with real samples, and were below instrumental detection limits for the majority of target compounds (Table S2). For PFBA (average blank level $0.3 \mathrm{ng} / \mathrm{L})$, PFBS (2.0 ng/ L), PFHxA (0.2 ng/L) and PFHxS (0.2 ng/L), low levels were detected in the blanks. The levels for these compounds were therefore reported on a blank corrected basis and the method detection limit was defined as the average plus three times the standard deviation of procedural blanks. Field blank samples were at the same levels as the procedural blanks, indicating no field contamination occurred during sampling. The positive detection of F-53B in the river water samples was further confirmed by comparing the quantifier and qualifier ion ratios between the samples and standard (SI Figure S1), and by using an ultrahigh performance liquid chromatography-Orbitrap 
Tribrid Fusion MS system (Thermo Fisher Scientific Inc., Waltham, MA, SI Figure S2).

Data Analysis and Riverine Mass Discharge Calculations. All concentrations of target analytes were presented as dissolved and blank corrected levels (see SI Tables S2 and S4). The water in two sampling sites were considered to be brackish (Yongding R: average salinity $0.2 \%$, Hai R: $0.9 \%$ ), but the reported levels were not salinity corrected. The average $\mathrm{pH}$ among the sampled rivers was $8.0 \pm 0.6$, while the median conductivity was $334 \mu \mathrm{S} / \mathrm{cm}$. Riverine mass discharges (tonnes/y) of PFASs were calculated by multiplying the measured concentrations $(\mathrm{ng} / \mathrm{L})$ with average water flows for the respective river $\left(\mathrm{L} / \mathrm{y}\right.$ ) (and multiplying by $10^{-15}$ to convert $\mathrm{ng}$ to tonnes). Riverine water flow data $\left(\mathrm{m}^{3} / \mathrm{s}\right)$ for the rivers in this study were compiled from accessible sources and are presented in SI Table S3. If applicable, annual average data were chosen from stations closest to the sampling sites, and the values from different sources were then averaged. The total riverine mass discharges of the different PFASs were calculated based on the arithmetic mean (AM) of the dissolved levels (<MDL being replaced with zero) from each analyzed river. The range of total riverine mass discharges were also calculated by multiplying either the lowest (lower bound) or highest (upper bound) concentrations measured in each river (SI Table S5) with the specific annual average river flow (SI Table S3).

In order to take advantage of previously reported data, we compiled concentrations of PFOA and PFOS in Chinese rivers from the scientific literature. The purpose of these expanded riverine mass discharge calculation was 2 -fold: (i) to complement the data generated in this sampling campaign with previous studies conducted in small, but highly contaminated rivers and (ii) to investigate the influence of variable concentrations on estimated riverine discharges from rivers which have been repeatedly sampled. The riverine mass discharges were either directly used if reported in the references or calculated using the reported levels multiplied by the estimated river flow (SI Table S5). If multiple sampling sites were reported for a specific river, then the average level was calculated for selected sites that were sampled closest to the river mouth. In order to evaluate the uncertainty of the estimated emissions, the lower (LB) and upper bound (UB) mass fluxes were calculated by using the lowest and highest mean concentrations for each river among the available studies (SI Table S5). Assumptions were made that the emissions have not changed significantly through the relatively short period of time (mostly from 2008 to 2014) between the studies and between sites along each river, as well as careful consideration of the analytical methodology and quality assurance applied. Calculations and statistical analysis were conducted using Microsoft Excel and Stata 13 (StataCorp LP).

\section{RESULTS AND DISCUSSION}

Concentrations and Homologue Profiles of PFAAs in Chinese Rivers. A total of 53 samples were collected from 19 rivers in this study and the levels are displayed in Figure 2 and SI Table S4. Among the PFAAs measured in this study; PFBA, PFPeA, PFHxA, PFHpA, PFOA, PFNA, PFDA, and PFOS were above the MDLs in all river samples, whereas PFBS and PFHxS were above the MDL in $32 \%$ and $13 \%$ of the samples, respectively. The total concentrations for the sum of ten PFAAs $\left(\Sigma_{10}\right.$ PFAAs $)$ for all samples averaged $106 \mathrm{ng} / \mathrm{L}(\mathrm{AM})$, whereas the median was $16.3 \mathrm{ng} / \mathrm{L}$ indicating a highly right-skewed distribution. The highest levels of $\Sigma_{10}$ PFAAs were found in

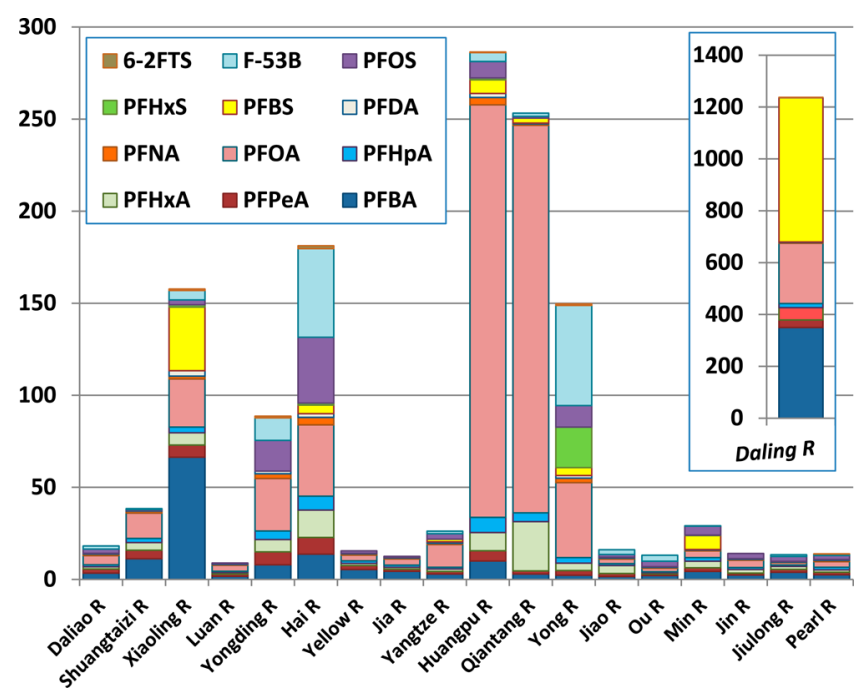

Figure 2. Average dissolved concentrations (ng/L) of $\Sigma_{12}$ PFASs in Chinese coastal rivers. Inset shows the PFAS levels from the Daling River.

Daling River (1240 ng/L) while the lowest levels were measured in Luan River ( $8.9 \mathrm{ng} / \mathrm{L})$. PFOA was typically the dominating compound in the majority of rivers (Figures 2 and 3). The highly variable concentrations and homologue profiles

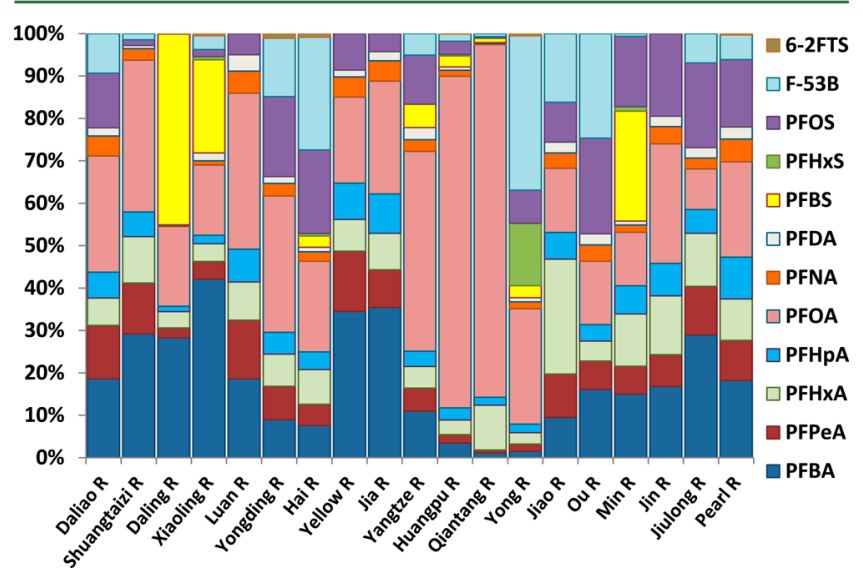

Figure 3. Composition profiles (based on dissolved concentrations seen in Figure 2) of analyzed PFASs in river samples.

of $\Sigma_{10}$ PFAAs demonstrate that the rivers are affected by different emission sources and that several rivers receive industrial discharges leading to elevated concentrations. $5,21,23,24,30$ Overall, the range of PFAA levels in the Chinese rivers (sampled in 2013) was comparable to those reported in rivers from other countries sampled between 2005 and 2010. For example, the PFOA levels for 14 major European rivers in 2005-2006 ranged $<0.65-23 \mathrm{ng} / \mathrm{L}$ with the exception of the Po River (200 ng/L) which was affected by a point source emission. ${ }^{17}$ Levels of PFOA in Japanese rivers in 2005 were on average $55 \mathrm{ng} / \mathrm{L}$ (geometric mean: $17 \mathrm{ng} / \mathrm{L}$ ). ${ }^{31}$ Also, the riverine levels of $\Sigma_{10}$ PFAAs from nonpoint source sites ranged from 4.5 to $102 \mathrm{ng} / \mathrm{L}$ (average $28.5 \mathrm{ng} / \mathrm{L}$ ) in Korea in $2010 .^{32}$

On a region-specific basis the highest levels were observed in rivers discharging to the Bohai Sea and East China Sea. The median $\Sigma_{10}$ PFAA levels of rivers around the Bohai Sea (Figure 1a) were $37.9 \mathrm{ng} / \mathrm{L}$ and were of a similar range to those 
previously reported for rivers in this region. ${ }^{24,33}$ The elevated $\Sigma_{10}$ PFAA levels found in the Daling River were dominated by PFBS (AM $556 \mathrm{ng} / \mathrm{L}$ ) followed by PFBA (AM $350 \mathrm{ng} / \mathrm{L}$ ) and PFOA (AM $233 \mathrm{ng} / \mathrm{L}$ ), which was different from most other rivers in this study (Figure 2 and 3). Zhu et al. measured the seasonal average levels $\Sigma_{10}$ PFAA (743-2460 ng/L) in Daling for the same year and also found that these three PFAAs were the dominating homologues in the same rank order, indicating significant contamination by the nearby fluorine chemical parks that produce low molecular weight fluorosurfactants (e.g., PFBS and PFOA) and fluoropolymers. ${ }^{34}$ The adjacent Xiaoling River also showed elevated levels of $\Sigma_{10}$ PFAAs $(152 \mathrm{ng} / \mathrm{L})$, and the similar composition profiles with a high contribution of PFBS (Figure 3) indicate that this river could be affected by the same fluorine chemical park as Daling River. Potential transport pathways could be atmospheric emissions of fluorinated surfactants from fluoropolymer manufacture ${ }^{35}$ or wastewater through drainage channels connecting the rivers.

Higher levels were found for the Shuangtaizi River ( $\Sigma_{10}$ PFAAs $37.9 \mathrm{ng} / \mathrm{L}$ ) compared to the Daliao River (16.5 ng/L), and PFOA and PFBA were shown to be the dominant PFAA. The Hai River contained the highest PFOS levels (AM $35.7 \mathrm{ng} / \mathrm{L}, \Sigma_{10}$ PFAAs $132 \mathrm{ng} / \mathrm{L}$ ) among all rivers in this study. The second highest PFOS level was found in the adjacent Yongding River (AM $16.7 \mathrm{ng} / \mathrm{L}, \quad \Sigma_{10}$ PFAAs $75.5 \mathrm{ng} / \mathrm{L}$ ). Tributaries of both rivers run through Beijing and they drain into the Bohai Sea in Tianjin city which has a large industrial sector (including metal plating and petrochemicals). The average level of $\Sigma_{10}$ PFAAs from the Yellow River was comparably low $(15.5 \mathrm{ng} / \mathrm{L})$ and was similar to the $\Sigma_{11}$ PFAAs of $13.2 \mathrm{ng} / \mathrm{L}$ reported in $2011 .^{24}$ Furthermore, comparable levels between Site 1 ( $\Sigma_{10}$ PFAAs $\left.15.9 \mathrm{ng} / \mathrm{L}\right)$ and Site $2(15.1 \mathrm{ng} / \mathrm{L})$ indicate that there were no significant sources at the eastern part of the Yellow River.

Among the three eastern sections of the Yangtze River that were sampled in this study, Site $3\left(\Sigma_{10}\right.$ PFAAs $\left.17.0 \mathrm{ng} / \mathrm{L}\right)$ and Site $4(20.0 \mathrm{ng} / \mathrm{L})$ showed comparable levels. Site 5 is situated at the river mouth and the level increased to $49.9 \mathrm{ng} / \mathrm{L}$, indicating significant sources such as fluorochemical manufacturing in the most eastern part of the river. ${ }^{23,30}$ The most abundant PFAA was PFOA (AM $12.3 \mathrm{ng} / \mathrm{L}$ ) contributing to about $40-56 \%$ of the total PFAAs in the Yangtze River (Figure 3 ). These ranges were comparable to another study from 2013 where levels of $\Sigma_{18}$ PFASs ranged 14-32 ng/L at the main stream of the Yangtze River, with PFOA and PFBS as the dominating homologues. ${ }^{26}$ The Huangpu River, which flows through Shanghai, could be a potential input source of PFASs to the Yangtze River mouth (Site 5). The $\Sigma_{10}$ PFAA level (281 $\mathrm{ng} / \mathrm{L}$ ) in Huangpu River was the second highest among all rivers in this study. Again PFOA was the most abundant homologue with the highest level $(352 \mathrm{ng} / \mathrm{L})$ near the center of Shanghai and a lower level ( $96 \mathrm{ng} / \mathrm{L})$ close to the confluence of the two rivers. There are several fluorochemical manufacturers located around Shanghai which could release PFASs to the two rivers, and other industrial activities such as electronics, printing and textile could also contribute to the high levels. ${ }^{36}$

High levels of PFOA (AM $211 \mathrm{ng} / \mathrm{L}$ ) were also found in Qiantang River together with elevated levels of PFHxA (AM $26.8 \mathrm{ng} / \mathrm{L}$ ). This river basin holds several fluorochemical manufacturers and is an important base for textile and clothing manufacturing. The high relative ratio of PFOA ( $83 \%$ of total PFASs, Figure 3) indicates its widespread contamination in this region. ${ }^{27,39}$ Lower levels of PFOA (57 ng/L) were found in another study in 2011 although the PFHxA levels were comparable $(31 \mathrm{ng} / \mathrm{L}){ }^{27}$ Among the six other rivers discharging into the East China Sea (Figure 1b), the Yong River showed the highest $\Sigma_{10}$ PFAA levels at $94.4 \mathrm{ng} / \mathrm{L}$. Elevated PFHxS (22.0 ng/L) and relatively high levels of PFOS $(11.7 \mathrm{ng} / \mathrm{L})$ in this river indicate higher input from specific sources such as manufacturing, chrome plating industries and/ or use of AFFF. ${ }^{5,22,38,39}$ This was almost twice as high compared to the levels $\left(\Sigma_{10}\right.$ PFASs $\left.53 \mathrm{ng} / \mathrm{L}\right)$ in the Yong River that was sampled in 2011. ${ }^{27}$ The PFAA levels (AM $28.9 \mathrm{ng} / \mathrm{L}$ ) in the Min River were dominated by PFBS $(7.5 \mathrm{ng} / \mathrm{L})$ followed by PFOS $(4.8 \mathrm{ng} / \mathrm{L})$. The composition profile for the Min River (Figure 3) fits well with the fact that a manufacturer of POSF and PBSF is located about $200 \mathrm{~km}$ upstream of this river. Relatively low levels of PFAAs were found in the Jiao (AM 13.5 ng/L), Ou (9.9 ng/L), Jin (14.1 ng/L), and Jiulong River (12.4 $\mathrm{ng} / \mathrm{L}$ ), and similar composition profiles were found for these rivers (Figure 3). The PFAA levels in the Pearl River were highest in Site 6 (AM $17.4 \mathrm{ng} / \mathrm{L})$ which was sampled in Guangzhou city, whereas Site $7\left(\Sigma_{10}\right.$ PFAA $\left.6.8 \mathrm{ng} / \mathrm{L}\right)$ is located at the mouth of the PRD, and these levels were similar to those reported by Liu et al. for the same time period $\left(\Sigma_{16}\right.$ PFAAs: 1.5-33.5 ng/L). ${ }^{40}$ Besides some minor fluorochemical manufacturers located in this region, the PRD is also one of the world's largest manufacturing hubs for consumer products such as electronics, clothing, furniture, and consumer goods. ${ }^{2,40}$ The expected river levels should be much higher if downstream fluorochemical industries are significant sources of PFASs to the environment. Therefore, by comparing the concentration trends and composition profiles of all rivers in this study and combining with the current knowledge of known manufacturing sites, our results strongly suggest that fluorochemical manufacturing are the most significant emission sources of PFCAs such as PFOA. For PFSAs such as PFOS, releases from industrial use such as chrome metal plating or AFFFs could be more significant (discussed below). These source trends for PFOA and PFOS have previously been predicted in models, and our extensive field results provide further validation to these models in predicting the most significant emission sources of PFAAs in China. ${ }^{5,8}$

PFOA Isomer Profiles. Branched isomers of PFOA were detected in 8 out of the 19 rivers. However, the concentrations were only within the dynamic range of \%br-PFOA (see Benskin et al. ${ }^{19}$ and SI) for Qiantang, Huanggpu, Daling, Xiaoling, Yongding, Yong River and the most downstream sampling point of Yangtze River (YZE5 in SI Table S4). The highest \% br-PFOA were observed in Qiantang (23.5\%), Daling (22.1\%) and Huangpu (18.8\%) River that also had the highest total PFOA concentrations, while a lower \%br-PFOA was observed in Yong (13.7\%), Xiaoling (13.3\%), Yangtze (11.7\%), and Yongding River (9.9\%). ECF PFOA from major Chinese producers have been reported to contain $20-26 \%$ br-PFOA ${ }^{21,22}$ which is similar to the historic ECF PFOA from $3 \mathrm{M}$ Co. of 22 $\pm 1.2 \%$ br-PFOA. $^{20,22}$ In contrast, PFOA produced by telomerization has a $>99.9 \%$ pure linear or iso- conformation. $^{20,23}$ Recent studies have demonstrated that abiotic fractionation in the aquatic environment has a negligible influence on observed isomer profiles in river water. ${ }^{21}$ Thus, the measured \%br-PFOA in river water samples should directly reflect the primary emission source(s). Given the range of brPFOA in technical products, the isomer profiles in Qiantang, Daling and Huangpu River demonstrate that the input of PFOA to these rivers was dominated by ECF sources. The 


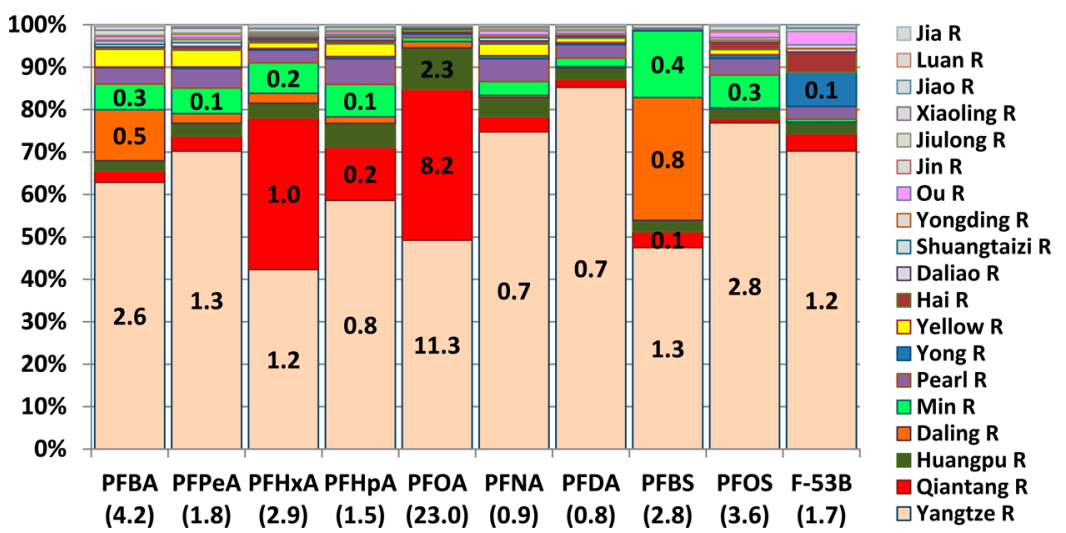

Figure 4. Relative contribution of individual rivers to the total Chinese annual riverine mass discharge of each PFAS based on arithmetic mean levels. The numbers on the bars are the estimated annual PFAS mass riverine discharges (tonnes/y). Rivers with a low contribution to the overall PFAS riverine mass discharge from China are shown in gray.

relative abundance of individual isomers from these rivers were also highly consistent with ECF-PFOA (iso- $>5 \mathrm{~m}->4 \mathrm{~m}->$ $3 \mathrm{~m}-\mathrm{PFOA}$ ) in all samples regardless of the \%br-PFOA (See SI Figure S3-S8). ECF has been the major synthesis route for technical PFOA in China, ${ }^{21,22}$ which is primarily used in fluoropolymer manufacture. The highly branched isomer profiles in Qiantang, Daling and Huangpu River, therefore, further corroborate that emissions from manufacture or industrial use of technical PFOA were likely the dominant sources to these rivers. The lower percentage of br-PFOA in the Yong, Xiaoling, Yangtze and Yongding, on the other hand, is most likely explained by the contribution from fluorotelomer (FT)-based sources of PFOA that dilute the ECF signature. On average approximately 3000 tonnes/year of FT-based substances have been imported or processed in China over the period 2004-2012 for usage primarily in the textile industry. ${ }^{8}$ Thus, the lower \%br-PFOA in rivers in rivers with limited input from fluoropolymer manufacture (Yong, Xiaoling, and Yongding) or large catchments (Yangtze) may therefore be attributed to transformation of FT-based precursors to PFOA. $^{20,21}$

Concentrations of Fluorinated Alternatives. In addition to PFAAs, the emerging fluorinated alternatives 6:2 FTS and F$53 \mathrm{~B}$ were detected in 21 and $51 \%$ of the rivers, respectively. The relatively high detection frequency of F-53B at comparable concentrations to those of PFOS (F-53B $<0.56-78.3 \mathrm{ng} / \mathrm{L}$; PFOS $0.4-55.0 \mathrm{ng} / \mathrm{L}$ ) suggests a widespread use of this fluorinated alternative in China. The highest levels of F-53B were found in the Yong River (AM 54.4 ng/L), Hai River (AM $48.2 \mathrm{ng} / \mathrm{L}$ ) and Yongding River (12.2 ng/L), confirming previous findings that the sources of this chemical are primarily located in the central eastern provinces with an intense concentration of metal plating facilities. ${ }^{41}$ The Ou River had an $\mathrm{AM}$ of $3.2 \mathrm{ng} / \mathrm{L}$ which was lower than previously reported levels from the same river $(11.7-54.7 \mathrm{ng} / \mathrm{L})$ sampled close to the effluent of a municipal wastewater treatment plant which receives wastewater from electroplating plants. ${ }^{12}$ F-53B was only found at the estuary site (Site 5, $6.7 \mathrm{ng} / \mathrm{L}$ ) of the Yangtze River, indicating potential sources at the river mouth and from the tributary, the Huangpu River (AM $4.8 \mathrm{ng} / \mathrm{L}$ ). A lower detection frequency of 6:2-FTS (21\%) indicates specialized production and usage of this chemical in China and/or the degradation of this substance after release to the environment. ${ }^{11}$ The Hai $(1.6 \mathrm{ng} / \mathrm{L})$ and Yongding River $(1.0 \mathrm{ng} / \mathrm{L})$ had the highest levels of 6:2-FTS, which also had relatively high levels of PFOS and F-53B. Samples with detectable levels of F53B and 6:2 FTS were positively correlated with PFOS (Spearman's rho 0.75 and 0.66 , respectively, $p<0.01$; Table S6). The positive correlation between these substances probably reflect similar emission sources originating from the usage in metal plating processes as mist suppressant. ${ }^{12}$ This conclusion is consistent with the ubiquitous detection of F-53B in sewage sludge and strong correlation with PFOS in China. ${ }^{41}$

Riverine Mass Discharges of PFASs from Chinese Rivers. The sum of riverine mass discharges and relative contribution of individual rivers from this study are illustrated in Figure 4. PFOA had the highest mass discharge rate at 23.0 tonnes/year (range 16.0-38.9 t/y), followed by PFBA (4.2 t/y, range 3.2-4.9 t/y), PFOS (3.6 t/y, 1.4-11.0 t/y), PFBS (2.8 t/ y, 1.2-5.0 t/y), PFHxA (2.9 t/y, 2.2-4.0 t/y), PFPeA (1.8 t/y, 1.4-2.4 t/y), PFHpA (1.5 t/y, 1.1-2.1 t/y), PFNA (0.9 t/y, $0.5-2.1 \mathrm{t} / \mathrm{y})$, PFDA $(0.8 \mathrm{t} / \mathrm{y}, 0.4-2.3 \mathrm{t} / \mathrm{y})$, and PFHxS $(0.09 \mathrm{t} /$ $\mathrm{y}, 0.02-0.19 \mathrm{t} / \mathrm{y})$. The largest contribution of total PFAS riverine mass discharges was from the Yangtze River, which contributed to $42-66 \%$ (AM $11.3 \mathrm{t} / \mathrm{y}$, range $6.7-25.5 \mathrm{t} / \mathrm{y}$ ) of the total PFOA mass discharge and 64-89\% (AM $2.8 \mathrm{t} / \mathrm{y}$, range 0.9-9.8 $\mathrm{t} / \mathrm{y}$ ) of the PFOS mass discharge. These estimates were somewhat higher than, but comparable to, those from another recent study in which the PFOA mass discharge was estimated at $6.8 \mathrm{t} / \mathrm{y}$ and PFOS at $0.88 \mathrm{t} / \mathrm{y} .{ }^{26}$ Because F-53B was only detected in one sample in the Yangtze River (Site 5, $6.7 \mathrm{ng} / \mathrm{L}$ ), the estimated riverine mass discharge based on arithmetic mean concentration $(1.2 \mathrm{t} / \mathrm{y})$ from this river is likely overestimated. The total F-53B mass discharge for all rivers combined ranged between 0.2 and $6.9 \mathrm{t} / \mathrm{y}$. Other rivers that significantly contributed to the total Chinese riverine mass discharges in this study were the Qiantang River, which contributed particularly to the mass discharge of PFOA (AM $8.2 \mathrm{t} / \mathrm{y}$, range $7.3-8.3 \mathrm{t} / \mathrm{y}$ ), PFHpA (AM $0.18 \mathrm{t} / \mathrm{y}, 0.15-0.20 \mathrm{t}$ / y) and PFHxA (AM 1.0 t/y, 0.7-1.1 t/y) and Daling River which transported a significant amount of PFBS (AM $0.8 \mathrm{t} / \mathrm{y}$, $18-62 \%$ of total mass discharge) and PFBA (AM $0.5 \mathrm{t} / \mathrm{y}, 11-$ $15 \%)$. Despite that the water flow rate at the mouths of the Qiantang and Daling River was only about $4 \%$ and $0.2 \%$ of the Yangtze River, the high emissions of specific PFAS homologues from point sources, as discussed above, make these rivers important contributors to the total Chinese riverine mass discharge. Although PFBS was only above the MDL in a third of the samples, its total mass discharge was still the fourth largest among the target compounds. The total riverine mass 
discharge of $\mathrm{C}_{4}-\mathrm{C}_{10}$ PFCAs in this study was $25-57 \mathrm{t} / \mathrm{y}$, which can be compared to theoretical emission estimates of 39.9-193 $\mathrm{t} / \mathrm{y} \mathrm{C}_{4}-\mathrm{C}_{14}$ PFCAs for China for the year 2013 (see SI Table S7). ${ }^{2}$ Furthermore, the calculated riverine mass discharges of PFCAs other than PFOA were mostly greater than the theoretical estimates, which might indicate a shift of production away from the C8 chemistry (Figure 4, SI Table S7). ${ }^{2}$

In order to provide a more comprehensive estimation of the total discharge from Chinese rivers, we compiled a database of riverine PFOA and PFOS levels from available reports. A total of 38 coastal rivers from 19 studies were included and the years of sampling ranged from 2002 to 2014 (Figure 5, SI Table S5).

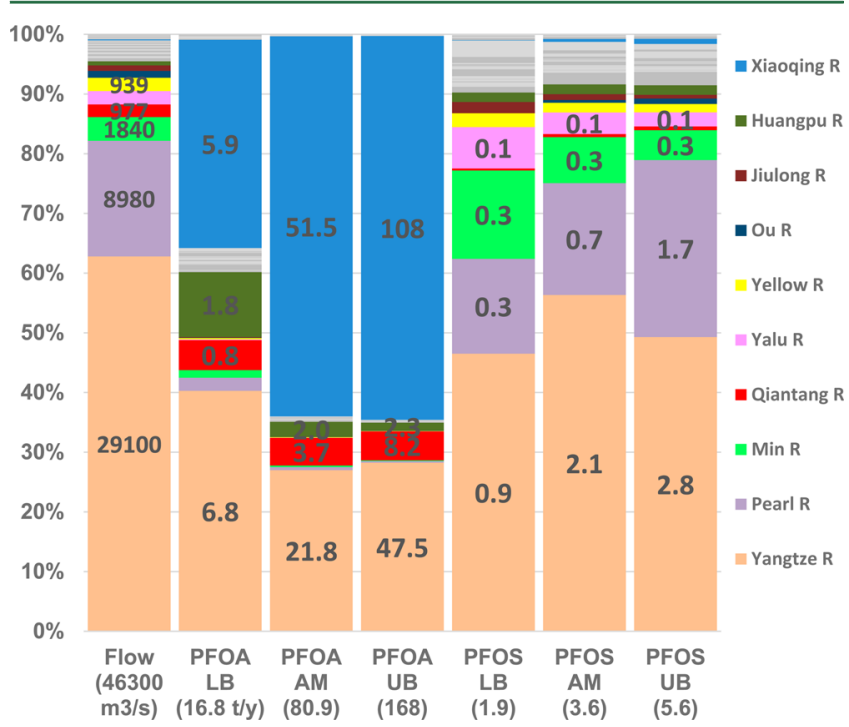

Figure 5. Relative contribution of rivers $(n=38)$ to the estimated total annual riverine mass discharge (tonnes/y) in China for PFOA and PFOS using arithmetic mean (AM), lower bound (LB) and upper bound (UB) values from this work and other studies (SI Table S5). Details on the calculations can be found in the "Materials and Methods" section. The total water flow at the river mouths $\left(\mathrm{m}^{3} / \mathrm{s}\right.$, weighted average from SI Table S5) and total annual riverine mass discharge of PFASs (tonnes/year) are shown in parentheses. Names of rivers with minor contributions are not shown and marked as gray. The average water flow rate and riverine mass discharge of PFASs for the Pearl River were calculated based on the sum of the Dongjiang, Beijiang, and Xijiang Rivers (see SI Table S5).

By including these additional studies the annual riverine mass discharge increased significantly for PFOA (AM 80.9 t/y, 16.8$168 \mathrm{t} / \mathrm{y})$, due to the large contribution from the Xiaoqing River (5.9-108 t/y) where extremely high concentrations have been measured in previous studies (see SI Table S5). In contrast, the low variability of annual riverine mass discharge of PFOS (AM $3.6 \mathrm{t} / \mathrm{y}, 1.9-5.6 \mathrm{t} / \mathrm{y}$ ) with the added measurements from additional rivers indicate no significant sources from other rivers outside of our study.

The range of field data based annual riverine mass discharges of PFOA (16.8-168 t/y) were in general agreement with theoretically estimated total annual emissions from China $(17.3-116 \mathrm{t} / \mathrm{y})$ for the year 2012 by Li et al. ${ }^{8}$ and $39.6-180 \mathrm{t} / \mathrm{y}$ for the year 2013 by Wang et al. (SI Table S7). ${ }^{2}$ For PFOS, riverine mass discharges were more than an order of magnitude lower than estimated industrial emissions of PFOS equivalents by Xie et al. $(70 \mathrm{t} / \mathrm{y})$ for the year 2010. ${ }^{5}$ This difference could partly be explained by the fact that PFOS precursors have not been completely transformed to PFOS in the environment and might also be predominantly distributed in the air. ${ }^{42,43}$ Thus, measurements of PFOS alone would inevitably lead to an underestimation of the total emissions of PFOS equivalents. The total annual riverine mass discharge of PFOS, as well as F$53 \mathrm{~B}$, could further be underestimated in this current study since these compounds could also be strongly sorbed to particulate matter in the water column and bottom sediment. ${ }^{12,21,4118,42,43}$ This characteristic property also leads to sorption onto the walls of the sampling vessels and the filter media, thus could further contribute to the lower calculated mass discharges. ${ }^{12,21,41}$ Furthermore, the low number of samples per site, temporal variation of PFAS levels and river flows of the different rivers could further contribute to the uncertainties in the emission calculations. The reported PFOA and PFOS levels as well as the annual average river flows could also vary considerably between different sources and years which further increases the variation of the annual mass discharge (SI Tables S3 and S5). A more comprehensive study which could address these drawbacks would therefore provide a more accurate overview of the riverine mass discharge from China.

Significance for Predicting the Global Trends of PFAS. The measurements performed in this study and compilation show that the total Chinese annual riverine mass discharges of PFAAs are mainly influenced by a few rivers with intensive fluorochemical manufacturing activities. On a global perspective, the Chinese annual riverine mass discharges of PFOA (including this and other studies) were higher than those estimated for European rivers (China: 16.8-168 t/y; Europe 14-30 t/y), whereas PFOS were lower in comparison (China: 1.9-5.6 t/y; Europe: 4-21 t/y). ${ }^{17,44}$ However, European data were mostly derived between 2005 and 2009 and might have been decreasing up to today due to decreased PFAS use/ production in Europe. The estimated wastewater derived mass discharges of PFOS, PFHpA, PFOA, and PFNA in Japanese rivers were about $3.6,2.6,5.6$, and $2.6 \mathrm{t} / \mathrm{y}$, respectively in $2005 .{ }^{31}$ In South Korea, the mean estimated national PFOA riverine mass discharges to the ocean were 0.9 and for PFOS $0.5 \mathrm{t} / \mathrm{y} .^{32}$ The production of PFOS in China is still fairly small compared to the total historic production of POSF-based substances (including PFOS and its precursors) between 1970 and 2002 which exceeded 100 ktonnes, of which between 6.8 ktonnes and 45.3 ktonnes were considered to have been emitted to the environment. ${ }^{16}$ The fairly limited production of PFOS in China may partly be a consequence of the restrictions on many consumer products in Europe and North America ${ }^{4}$ which makes it difficult to find an export market for POSFbased products. China has, however, exported POSF to Brazil for the production of Sulfluramid. ${ }^{45}$ In this study, the annual riverine mass discharge of $\mathrm{F}-53 \mathrm{~B}$ was between 0.2 and $6.9 \mathrm{t} / \mathrm{y}$ (AM $1.7 \mathrm{t} / \mathrm{y}$ ), which seems reasonable given that the estimated use by the metal plating industry in China were about 20-30 tonnes in 2009.

The unique empirical data set presented here, together with the reviewed studies included in the total Chinese riverine mass discharge estimates, demonstrate that emissions from Chinese point sources likely dominate the global emissions of several legacy PFASs (notably PFOA) as well as fluorinated alternatives (notably F-53B). The ongoing emission and riverine mass discharge of large quantities of PFOA in China could impede ongoing efforts elsewhere to reduce PFOA global contamination and exposure to wildlife and humans. At the same time, replacement PFASs such as F-53B are also emitted and discharged in Chinese river estuaries in significant 
quantities. Although China is the only country with a documented use of $\mathrm{F}-53 \mathrm{~B},{ }^{12,41}$ its persistence and transport potential could lead to a new global contamination problem.

\section{ASSOCIATED CONTENT}

\section{S Supporting Information}

The Supporting Information is available free of charge on the ACS Publications website at DOI: 10.1021/acs.est.6b03752.

Detailed information on the sample pretreatment, chemical analysis, $\mathrm{QA} / \mathrm{QC}$, river flow data, river sample concentrations. Additional tables and figures for the compiled Chinese river data, chromatograms, mass spectra and theoretical emission estimates (PDF) (XLSX)

\section{AUTHOR INFORMATION}

\section{Corresponding Author}

*Phone: +46 19-303462; E-mail: thanh.wang@oru.se.

Notes

The authors declare no competing financial interest.

\section{ACKNOWLEDGMENTS}

Funding was received from the National Natural Science Foundation (21361140359), External Cooperation Program of the Chinese Academy of Sciences (GJHZ1202) and the Norwegian Research Council. We appreciate the help of Zhenlan Xu, Yan Gao, Yongfeng Lin and Ting Ruan, Qiuquan Wang, Xinglong Jin, Liangqia Guo, Zhen Zhang, Xialin $\mathrm{Hu}$ and others that participated in the sampling campaign. Dr. Zhanyun Wang is thanked for the help with emission data.

\section{REFERENCES}

(1) Lindstrom, A. B.; Strynar, M. J.; Libelo, E. L. Polyfluorinated compounds: past, present, and future. Environ. Sci. Technol. 2011, 45 (19), 7954-61.

(2) Wang, Z.; Cousins, I. T.; Scheringer, M.; Buck, R. C.; Hungerbühler, K. Global emission inventories for C4-C14 perfluoroalkyl carboxylic acid (PFCA) homologues from 1951 to 2030, Part I: production and emissions from quantifiable sources. Environ. Int. 2014, $70(0), 62-75$.

(3) Smart, B., Characteristics of C-F systems. In Organofluorine Chemistry: Principles and Commercial Applications, Banks, R.; Smart, B.; Tatlow, J., Eds.; Springer US: New York, 1994; pp 57-88.

(4) Wang, T.; Wang, Y.; Liao, C.; Cai, Y.; Jiang, G. Perspectives on the inclusion of perfluorooctane sulfonate into the Stockholm Convention on Persistent Organic Pollutants. Environ. Sci. Technol. 2009, 43 (14), 5171-5.

(5) Xie, S.; Wang, T.; Liu, S.; Jones, K. C.; Sweetman, A. J.; Lu, Y. Industrial source identification and emission estimation of perfluorooctane sulfonate in China. Environ. Int. 2013, 52, 1-8.

(6) Xie, S.; Lu, Y.; Wang, T.; Liu, S.; Jones, K.; Sweetman, A. Estimation of PFOS emission from domestic sources in the eastern coastal region of China. Environ. Int. 2013, 59, 336-343.

(7) Zhang, L.; Liu, J.; Hu, J.; Liu, C.; Guo, W.; Wang, Q.; Wang, H. The inventory of sources, environmental releases and risk assessment for perfluorooctane sulfonate in China. Environ. Pollut. 2012, 165, 193-198.

(8) Li, L.; Zhai, Z.; Liu, J.; Hu, J. Estimating industrial and domestic environmental releases of perfluorooctanoic acid and its salts in China from 2004 to 2012. Chemosphere 2015, 129, 100-109.

(9) Wang, Z.; Cousins, I. T.; Scheringer, M.; Hungerbühler, K. Fluorinated alternatives to long-chain perfluoroalkyl carboxylic acids (PFCAs), perfluoroalkane sulfonic acids (PFSAs) and their potential precursors. Environ. Int. 2013, 60 (0), 242-248.
(10) Heydebreck, F.; Tang, J.; Xie, Z.; Ebinghaus, R. Alternative and Legacy Perfluoroalkyl Substances: Differences between European and Chinese River/Estuary Systems. Environ. Sci. Technol. 2015, 49 (14), 8386-8395.

(11) Yang, X.; Huang, J.; Zhang, K.; Yu, G.; Deng, S.; Wang, B. Stability of 6:2 fluorotelomer sulfonate in advanced oxidation processes: degradation kinetics and pathway. Environ. Sci. Pollut. Res. 2014, 21 (6), 4634-4642.

(12) Wang, S.; Huang, J.; Yang, Y.; Hui, Y.; Ge, Y.; Larssen, T.; Yu, G.; Deng, S.; Wang, B.; Harman, C. First Report of a Chinese PFOS Alternative Overlooked for 30 Years: Its Toxicity, Persistence, and Presence in the Environment. Environ. Sci. Technol. 2013, 47 (18), 10163-10170.

(13) Ellis, D. A.; Martin, J. W.; De Silva, A. O.; Mabury, S. A.; Hurley, M. D.; Sulbaek Andersen, M. P.; Wallington, T. J. Degradation of fluorotelomer alcohols: a likely atmospheric source of perfluorinated carboxylic acids. Environ. Sci. Technol. 2004, 38 (12), 3316-21.

(14) Wang, Z.; Cousins, I. T.; Scheringer, M.; Buck, R. C.; Hungerbühler, K. Global emission inventories for C4-C14 perfluoroalkyl carboxylic acid (PFCA) homologues from 1951 to 2030, part II: The remaining pieces of the puzzle. Environ. Int. 2014, 69, 166-176.

(15) Prevedouros, K.; Cousins, I. T.; Buck, R. C.; Korzeniowski, S. H. Sources, Fate and Transport of Perfluorocarboxylates. Environ. Sci. Technol. 2005, 40 (1), 32-44.

(16) Paul, A. G.; Jones, K. C.; Sweetman, A. J. A First Global Production, Emission, And Environmental Inventory For Perfluorooctane Sulfonate. Environ. Sci. Technol. 2008, 43 (2), 386-392.

(17) McLachlan, M. S.; Holmstrom, K. E.; Reth, M.; Berger, U. Riverine discharge of perfluorinated carboxylates from the European continent. Environ. Sci. Technol. 2007, 41 (21), 7260-5.

(18) Filipovic, M.; Laudon, H.; McLachlan, M. S.; Berger, U. Mass Balance of Perfluorinated Alkyl Acids in a Pristine Boreal Catchment. Environ. Sci. Technol. 2015, 49 (20), 12127-12135.

(19) Benskin, J. P.; Yeung, L. W. Y.; Yamashita, N.; Taniyasu, S.; Lam, P. K. S.; Martin, J. W. Perfluorinated Acid Isomer Profiling in Water and Quantitative Assessment of Manufacturing Source. Environ. Sci. Technol. 2010, 44 (23), 9049-9054.

(20) Benskin, J. P.; Phillips, V.; St. Louis, V. L.; Martin, J. W. Source Elucidation of Perfluorinated Carboxylic Acids in Remote Alpine Lake Sediment Cores. Environ. Sci. Technol. 2011, 45 (17), 7188-7194.

(21) Shi, Y.; Vestergren, R.; Xu, L.; Song, X.; Niu, X.; Zhang, C.; Cai, $\mathrm{Y}$. Characterizing direct emissions of perfluoroalkyl substances from ongoing fluoropolymer production sources: A spatial trend study of Xiaoqing River, China. Environ. Pollut. 2015, 206, 104-112.

(22) Jiang, W.; Zhang, Y.; Yang, L.; Chu, X.; Zhu, L. Perfluoroalkyl acids (PFAAs) with isomer analysis in the commercial PFOS and PFOA products in China. Chemosphere 2015, 127, 180-187.

(23) Jin, H.; Zhang, Y.; Zhu, L.; Martin, J. W. Isomer Profiles of Perfluoroalkyl Substances in Water and Soil Surrounding a Chinese Fluorochemical Manufacturing Park. Environ. Sci. Technol. 2015, 49 (8), 4946-4954.

(24) Wang, P.; Lu, Y.; Wang, T.; Fu, Y.; Zhu, Z.; Liu, S.; Xie, S.; Xiao, Y.; Giesy, J. P. Occurrence and transport of 17 perfluoroalkyl acids in 12 coastal rivers in south Bohai coastal region of China with concentrated fluoropolymer facilities. Environ. Pollut. 2014, 190 (0), $115-122$.

(25) Chen, C.; Wang, T.; Khim, J. S.; Luo, W.; Jiao, W.; Lu, Y.; Naile, J. E.; Hu, W.; Zhang, X.; Geng, J.; Bi, C.; Li, J.; Giesy, J. P. Perfluorinated compounds in water and sediment from coastal regions of the northern Bohai Sea, China. Chem. Ecol. 2011, 27 (2), 165-176.

(26) Pan, C.-G.; Ying, G.-G.; Zhao, J.-L.; Liu, Y.-S.; Jiang, Y.-X.; Zhang, Q.-Q. Spatiotemporal distribution and mass loadings of perfluoroalkyl substances in the Yangtze River of China. Sci. Total Environ. 2014, 493, 580-587.

(27) Lu, Z.; Song, L.; Zhao, Z.; Ma, Y.; Wang, J.; Yang, H.; Ma, H.; Cai, M.; Codling, G.; Ebinghaus, R.; Xie, Z.; Giesy, J. P. Occurrence and trends in concentrations of perfluoroalkyl substances (PFASs) in surface waters of eastern China. Chemosphere 2015, 119, 820-827. 
(28) Benskin, J. P.; Ikonomou, M. G.; Woudneh, M. B.; Cosgrove, J. R. Rapid characterization of perfluoralkyl carboxylate, sulfonate, and sulfonamide isomers by high-performance liquid chromatographytandem mass spectrometry. J. Chromatogr A 2012, 1247, 165-170.

(29) Chandramouli, B.; Benskin, J. P.; Hamilton, M. C.; Cosgrove, J. R. Sorption of per- and polyfluoroalkyl substances (PFASs) on filter media: implications for phase partitioning studies. Environ. Toxicol. Chem. 2015, 34 (1), 30-6.

(30) Shan, G.; Wei, M.; Zhu, L.; Liu, Z.; Zhang, Y. Concentration profiles and spatial distribution of perfluoroalkyl substances in an industrial center with condensed fluorochemical facilities. Sci. Total Environ. 2014, 490, 351-359.

(31) Murakami, M.; Imamura, E.; Shinohara, H.; Kiri, K.; Muramatsu, Y.; Harada, A.; Takada, H. Occurrence and sources of perfluorinated surfactants in rivers in Japan. Environ. Sci. Technol. 2008, 42 (17), $6566-72$.

(32) Kim, S.-K.; Li, D.; Shoeib, M.; Zoh, K.-D. Contribution of diffuse inputs to the aqueous mass load of perfluoroalkyl acids in river and stream catchments in Korea. Sci. Total Environ. 2014, 470-471, $1430-1440$.

(33) Wang, T.; Khim, J. S.; Chen, C.; Naile, J. E.; Lu, Y.; Kannan, K.; Park, J.; Luo, W.; Jiao, W.; Hu, W.; Giesy, J. P. Perfluorinated compounds in surface waters from Northern China: Comparison to level of industrialization. Environ. Int. 2012, 42, 37-46.

(34) Zhu, Z.; Wang, T.; Meng, J.; Wang, P.; Li, Q.; Lu, Y. Perfluoroalkyl substances in the Daling River with concentrated fluorine industries in China: seasonal variation, mass flow, and risk assessment. Environ. Sci. Pollut. Res. 2015, 22 (13), 10009-10018.

(35) Barton, C. A.; Butler, L. E.; Zarzecki, C. J.; Flaherty, J.; Kaiser, M. Characterizing Perfluorooctanoate in Ambient Air near the Fence Line of a Manufacturing Facility: Comparing Modeled and Monitored Values. J. Air Waste Manage. Assoc. 2006, 56 (1), 48-55.

(36) Bao, J.; Liu, W.; Liu, L.; Jin, Y.; Ran, X.; Zhang, Z. Perfluorinated compounds in urban river sediments from Guangzhou and Shanghai of China. Chemosphere 2010, 80 (2), 123-130.

(37) Chen, C.; Lu, Y.; Zhang, X.; Geng, J.; Wang, T.; Shi, Y.; Hu, W.; $\mathrm{Li}, \mathrm{J}$. A review of spatial and temporal assessment of PFOS and PFOA contamination in China. Chem. Ecol. 2009, 25 (3), 163-177.

(38) Fu, J.; Gao, Y.; Wang, T.; Liang, Y.; Zhang, A.; Wang, Y.; Jiang, G., Elevated levels of perfluoroalkyl acids in family members of occupationally exposed workers: the importance of dust transfer. Sci. Rep. 2015, 5.931310.1038/srep09313

(39) Hu, X. C.; Andrews, D. Q.; Lindstrom, A. B.; Bruton, T. A.; Schaider, L. A.; Grandjean, P.; Lohmann, R.; Carignan, C. C.; Blum, A.; Balan, S. A.; Higgins, C. P.; Sunderland, E. M. Detection of Polyand Perfluoroalkyl Substances (PFASs) in U.S. Drinking Water Linked to Industrial Sites, Military Fire Training Areas, and Wastewater Treatment Plants. Environ. Sci. Technol. Lett. 2016, DOI: 10.1021/ acs.estlett.6b00260.

(40) Liu, B.; Zhang, H.; Xie, L.; Li, J.; Wang, X.; Zhao, L.; Wang, Y.; Yang, B. Spatial distribution and partition of perfluoroalkyl acids (PFAAs) in rivers of the Pearl River Delta, southern China. Sci. Total Environ. 2015, 524-525, 1-7.

(41) Ruan, T.; Lin, Y.; Wang, T.; Liu, R.; Jiang, G. Identification of Novel Polyfluorinated Ether Sulfonates as PFOS Alternatives in Municipal Sewage Sludge in China. Environ. Sci. Technol. 2015, 49 (11), 6519-6527.

(42) Benskin, J. P.; Ikonomou, M. G.; Gobas, F. A. P. C.; Begley, T. H.; Woudneh, M. B.; Cosgrove, J. R. Biodegradation of N-Ethyl Perfluorooctane Sulfonamido Ethanol (EtFOSE) and EtFOSE-Based Phosphate Diester (SAmPAP Diester) in Marine Sediments. Environ. Sci. Technol. 2013, 47 (3), 1381-1389.

(43) Martin, J. W.; Asher, B. J.; Beesoon, S.; Benskin, J. P.; Ross, M. S. PFOS or PreFOS? Are perfluorooctane sulfonate precursors (PreFOS) important determinants of human and environmental perfluorooctane sulfonate (PFOS) exposure? J. Environ. Monit. 2010, 12 (11), 1979-2004.
(44) Pistocchi, A.; Loos, R. A map of European emissions and concentrations of PFOS and PFOA. Environ. Sci. Technol. 2009, 43 (24), 9237-44.

(45) Löfstedt Gilljam, J.; Leonel, J.; Cousins, I. T.; Benskin, J. P. Is Ongoing Sulfluramid Use in South America a Significant Source of Perfluorooctanesulfonate (PFOS)? Production Inventories, Environmental Fate, and Local Occurrence. Environ. Sci. Technol. 2016, 50 (2), $653-659$. 